\title{
Komputasi Budaya Untuk Pencarian Gambar Semantik Pada Lukisan Budaya Indonesia Dengan Deteksi Dan Informasi Aliran Lukisan
}

\author{
Ratri Cahyaning Winedhar \\ Program Studi Magister Terapan \\ Teknik Informatika dan Komputer \\ Politeknik Elektronika Negeri Surabaya \\ Surabaya,Indonesia \\ ratri.c.winedhar@gmail.com \\ Arvita Agus Kurnasari \\ Politeknik Negeri Jember \\ Jember,Indonesia \\ arvita@polije.ac.id
}

\author{
Ali Ridho Barakbah \\ Politeknik Elektronika Negeri Surabaya \\ Surabaya,Indonesia \\ ridho@pens.ac.id
}

\author{
Achmad Basuki \\ Politeknik Elektronika Negeri Surabaya \\ Surabaya,Indonesia \\ basuki@pens.ac.id
}

\begin{abstract}
Paintings are complex images that reflect the artist's observations and feelings towards the environment. This condition would need detection systems expand cultural image for the ordinary people who lack the artistic experience will be difficult to get an impression of his paintings. Therefore, researchers emphasize the application of Indonesian cultural paintings into mobile applications. The proposed system has been implemented in 239 Indonesian cultural paintings consisting of five categories of painting styles. The categories are abstractionism, naturalism, expressionism, realism, and romanticism. The system extracts 3 features, which are color, shape, and texture features. Extraction of color features using Histogram 3D Color Vector Quantization. Extraction of shape features using the Connected Component Labeling Algorithm (CCL) by calculating the value of area, equivalent diameter, area, convex hull, solidity, eccentricity, and perimeter of each object. Extraction of texture features using Gabor Transformation with 40 kernels. For the extraction of impressions, a survey was conducted on several people regarding the impression of Indonesian cultural paintings. This survey was conducted on respondents who understand painting, such as painters, observers of painting, and people who are involved in the world of fine arts. In showing the painting style, the researcher uses a classification process using K-Nearest Neighbor. The experimental results show the color feature as the best feature in the impression query (Abstract)
\end{abstract}

Keywords - Image feature extraction, Cultural computing, image search painting, impression similarity, painting style

\footnotetext{
Abstrak- Lukisan merupakan salah satu gambaran kompleks yang mencerminkan pengamatan dan perasaan seniman terhadap lingkungan. Kondisi ini memperluas kebutuhan akan sistem pendeteksi citra budaya karena masyarakat awam yang kurang memiliki pengalaman artistik akan sulit mendapatkan kesan lukisannya. Oleh karena itu, peneliti menekankan penerapan lukisan budaya Indonesia ke dalam aplikasi mobile. Sistem yang diusulkan telah diimplementasikan pada 239 lukisan budaya Indonesia yang terdiri dari lima kategori gaya lukisan. Kategorinya adalah abstraksionisme, naturalisme, ekspresionisme, realisme, dan romantisme. Sistem mengekstrak 3 fitur, yaitu fitur warna, bentuk, dan tekstur. Ekstraksi ciri warna menggunakan Histogram 3D Color Vector Quantization. Ekstraksi fitur
}

bentuk menggunakan Connected Component Labeling Algorithm (CCL) dengan menghitung nilai area, diameter setara, luas, convex hull, soliditas, eksentrisitas, dan perimeter masing-masing objek. Ekstraksi fitur tekstur menggunakan Gabor Transformation dengan 40 kernel. Sedangkan untuk ekstraksi impresi dilakukan survey terhadap beberapa orang tentang impresi lukisan budaya Indonesia. Survei ini dilakukan terhadap responden yang memahami seni lukis seperti pelukis, pemerhati lukisan, dan orang-orang yang berkecimpung di dunia seni rupa. Untuk menunjukkan gaya lukisan peneliti menggunakan proses klasifikasi menggunakan K-Nearest Neighbor. Hasil eksperimen menunjukan fitur warna sebagai fitur terbaik dalam impression query (Abstrak)

Keywords- Image feature extraction, Cultural computing, image search painting, impression similarity, painting style.

\section{PENDAHULUAN}

Lukisan merupakan karya dari seni lukis yang tercipta dari hasil imajinasi seniman yang diekspresikan melalui media garis, warna, tekstur, gelap terang, maupun bidang dan bentuk. Seni lukis ialah seni yang mengapresiasikan kreatifitas seorang seniman melalui bidang dua dimensi, seperti kanvas, papan, kertas dan sebagainya. Melukis adalah kegiatan mengolah medium dua dimensi atau permukaan dari objek tiga dimensi untuk mendapat kesan tertentu. Melukis adalah tradisi artistik yang mengintegrasikan filosofi, estetika, dan nilai budaya dan kepercayaan. Sebagai contoh lukisan budaya Indonesia mengekspos keindahan alam dan keragaman budaya di Indonesia. Selain itu lukisan bercerita tentang isu atau kebijaksanaan tertentu yang menarik para seniman. Citra ini dipengaruhi oleh pemahaman seniman terhadap lingkungan sekitarnya. Citra satu objek bisa berbeda dalam beberapa lukisan tergantung pada pemahaman budaya di masyarakat. Oleh karena itu, menghargai seni adalah hal yang bermanfaat bagi manusia.

Dengan memahami seni dan budaya daerah, kita akan dapat mengetahui dan menghormati adanya keanekaragaman berbudaya dan kesadaran berbudaya. Hal tersebut dapat mengembangkan kemampuan berpikir analisis, evaluasi dan pencarian masalah. Apresiasi seni lukis dapat dilakukan dengan mengamati objek secara langsung kemudian memahami kesan dari lukisan tersebut. Namun untuk saat ini 
masih dilakukan dengan mengamati objek secara langsung. Apresiasi lukisan perlu diperkuat dengan sentuhan teknologi untuk memahami makna yang terkandung dari lukisan tersebut.

Implementasi budaya ke dalam teknologi disebut dengan komputasi budaya. Komputasi budaya merupakan penelitian yang bertujuan untuk mengatasi berbagai masalah budaya di masyarakat dengan teknologi informasi dan komunikasi. [1] dalam penelitiannya komputasi budaya diaplikasikan ke dalam batik Madura untuk memperoleh impressi dari motif batik Madura melalui aplikasi mobile. Impressi diperoleh dari hasil ektraksi fitur warna, bentuk, dan area. Selain itu penelitian lain tentang komputasi budaya dilakukan oleh [2] tentang makna simbolik dari gambar songket. Untuk memperoleh impressi dari gambar songket dilakukan symbolic meaning extraction dan analytical aggregation dari fitur warna dan fitur bentuk. Penelitian sebelumnya menjelaskan tentang sistem aplikasi berbasis andoid untuk mendeteksi impressi dari lukisan budaya Indonesia memberikan kesan lukisan yang representatif dengan menyediakan metrik kesan warna yang diambil dari survei publik dan implementasikan untuk aplikasi seluler dan model ini menyediakan fungsi analitis untuk menghasilkan kesan perwakilan dari permintaan gambar [3]. Penelitian mengukur kesamaan gambar query dengann gambar database untuk menemukan rangking tertinggi kesamaan gambar yang diambil. Untuk eksperimen, peneliti menerapkan sistem ke 248 gambar lukisan budaya Indonesia yang terdiri dari 5 kategori antara lain abstraksionisme, naturalisme, expresionisme, realisme dan romantisme. Peneliti menggunakan metode yang sama pada ekstraksi fitur warna yaitu menggunakan 3D Color Vector Quantization [4].

Dari paparan di atas, maka peneliti bermaksud untuk mengaplikasikan lukisan budaya Indonesia ke dalam aplikasi mobile. Sehingga pembaruan dari penelitian sebelumnya yaitu penelitian ini lebih memudahkan dalam memperoleh impressi dari lukisan budaya Indonesia melalui pendekatan fitur warna, bentuk dan tekstur. Selain menghasilkan output berupa impressi dari lukisan budaya Indonesia, sistem ini juga menampilkan pendekatan dari gambar query, serta pendeteksian aliran dari lukisan budaya Indonesia.

\section{METODE PENELITIAN}

Metodologi penelitian yang diimplementasikan terbagi ke dalam beberapa tahapan, ditunjukkan dengan gambaran sistem pada Gambar 1.

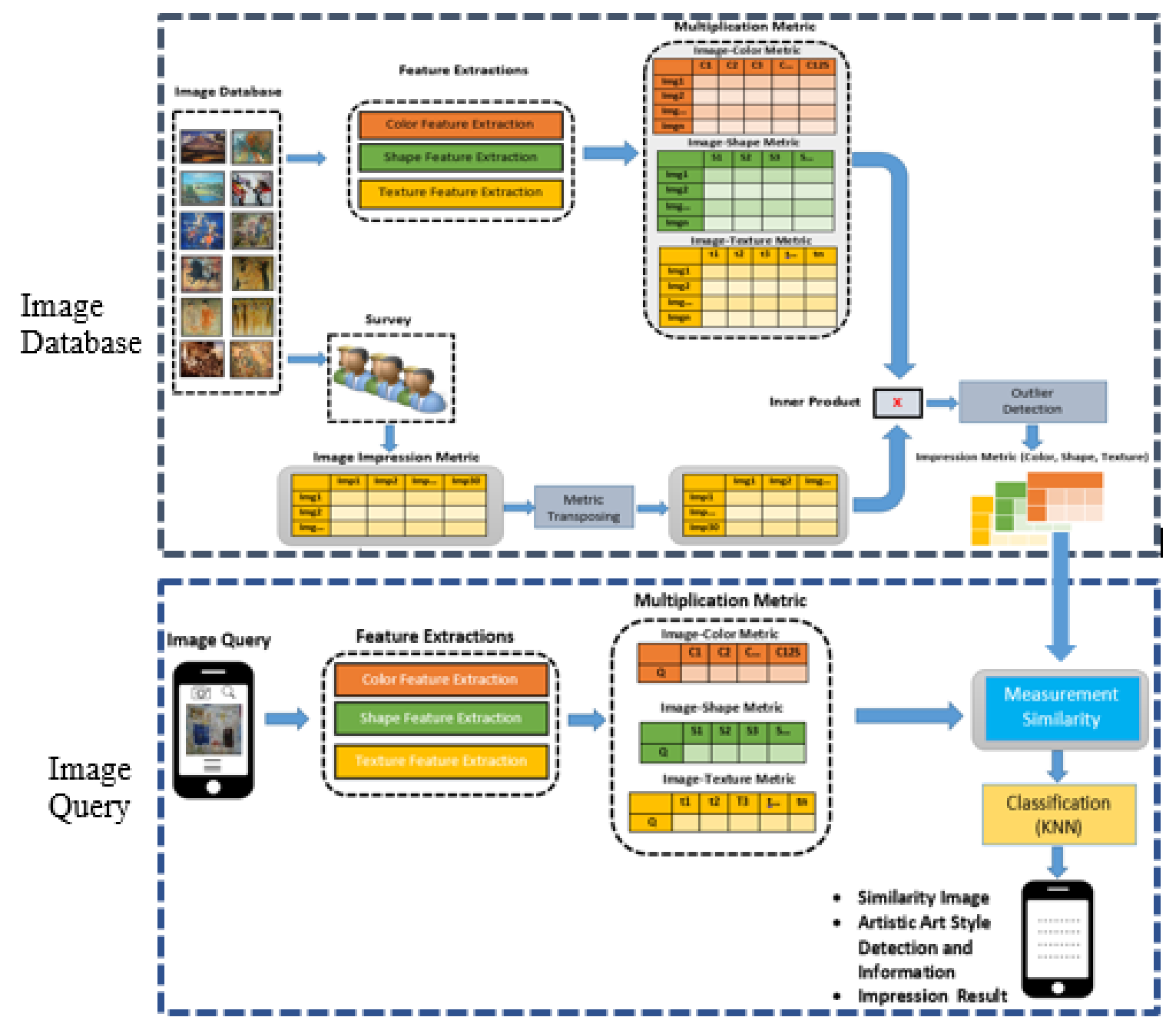

Gambar. 1.Perancangan Sistem 
Penelitian ini menggunakan proses ekstraksi fitur warna, fitur bentuk dan tekstur untuk memperoleh impresi dari lukisan budaya Indonesia. Selain menghasilkan output impresi dari lukisan budaya Indonesia, sistem ini juga akan menampilkan pendekatan dari gambar query, dan aliran dari lukisan budaya Indonesia. Sistem ini akan menampilkan sebuah alat pendukung untuk menghasilkan tiga output antara lain, informasi impressi dari lukisan budaya Indonesia, pengelompokan aliran lukisan, dan pendekatan gambar lukisan.

\section{A. Koleksi Gambar}

Data yang digunakan berupa lukisan budaya Indonesia yang terdiri dari 239 lukisan yang masing-masing dikelompokkan kedalam lima kategori gaya lukisan. Kategori lukisan yaitu abstraksionisme, naturalisme, ekspresionisme, realisme, dan romantisme [5].

\section{B. Ekstraksi Fitur Warna}

Ekstraksi fitur warna menggunakan Histogram Tiga Dimensi (3D) Color Vector Quantization dari ruang warna RGB [6]. Dari ruang warna RGB menjadi ukuran kuantisasi ruang 64x64x64 sampai 125 posisi R68. Hasil ekstraksi fitur warna berupa metrik fitur metadata.

$$
H_{i}=\sum_{j=1}^{j=n} H_{j}\left\{\begin{array}{l}
H_{j}=1 \leftarrow \min (D(R G B j, R G B i)) \\
H_{j}=0 \leftarrow \text { otherwise }
\end{array}\right.
$$

$\mathrm{Hi}=$ Histogram dari 125 posisi dalam ruang warna RGB $\mathrm{Hj}=$ piksel gambar, $\mathrm{n}$ adalah jumlah piksel,

D (RGBj, RGBi) adalah jarak antara warna pixel RGB dan warna RGB posisi j 125.

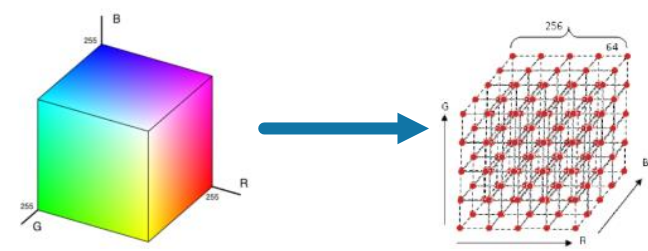

Gambar. 2.Ilustrasi 3D-Color Vector Quantization RGB [3]

C. Ekstraksi Fitur Warna

Ekstraksi fitur bentuk adalah proses ekstraksi bentuk dari lukisan budaya menggunakan Connected Component Labeling (CCL). Tahap awal untuk fitur ekstraksi ini menerapkan deteksi tepi menggunakan canny detection yang bertujuan untuk menghaluskan gambar dan noise kemudian didapatkan ekstrak kontur. Dari kontur tersebut diolah untuk menjadi nilai area, equevalent diameter, extent, convex hull, solidity, perimeter dan eccentricity dari masing-masing objek. Perhitungan yang diterapkan untuk mepresentasikan masing-masing pixel ke dalam matrik bentuk peneliti menggunakan mean $(\mu)$, median, standard deviation $(\sigma)$, skewness (s) variance $(\sigma 2)[6]$.

$$
\begin{aligned}
\mu_{i} & =\frac{1}{N} \sum_{j=1}^{N} X_{i j} \\
\sigma_{i} & =\left(\frac{1}{N} \sum_{j=1}^{N}\left(X_{i j}-\mu_{i}\right)^{2}\right)^{\frac{1}{2}} \\
\sigma_{i} & =\frac{1}{N} \sum_{j=1}^{N}\left(X_{i j}-\mu_{i}\right)^{2}
\end{aligned}
$$

$$
s_{i}=\frac{1}{N} \sum_{j=1}^{N}\left[\frac{x_{i j}-\mu_{i}}{\sigma_{i}}\right]^{3}
$$

Keterangan:

$X_{i j}$ merupakan value dari komponen warna $i$ pada pixel gambar j, dan $\mathrm{N}$ merupakan jumlah dari pixel gambar.

\section{Ekstraksi Fitur Tekstur}

Transformasi Gabor banyak digunakan dalam pengolahan citra dengan tujuan ekstraksi fitur dan analisis tekstur. Berdasarkan fakta bahwa transformasi Gabor adalah selektif terhadap orientasi [7], peneliti telah menerapkan subband dekomposisi dengan empat orientasi yang berbeda. Gambar 3 menampilkan kernel digunakan untuk membuat subbands Gabor [8].

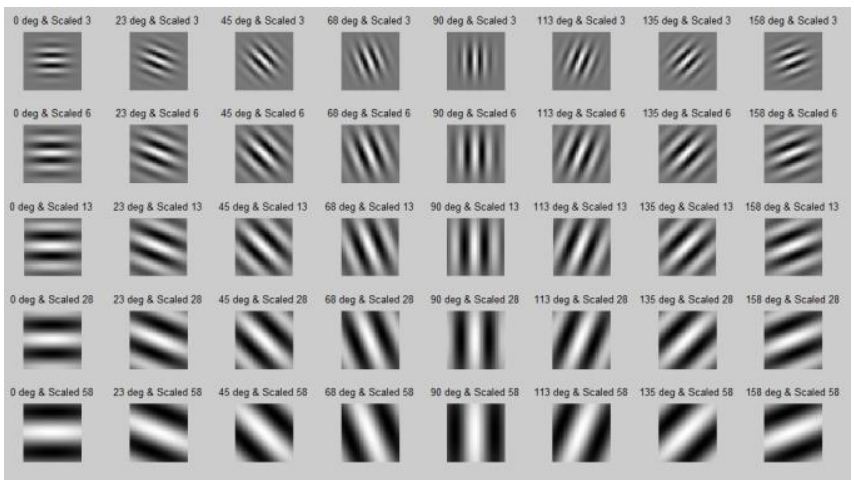

Gambar. 3.Kernel Gabor

E. Multiplication Impression Metric

lukisan, dan mahasiswa seni rupa Universitas Negeri Surabaya. Hal ini dilakukan agar data penilaian terhadap impressi lukisan lebih akurat. Total user pada survey ini adalah 101 responden. Hasil survey adalah berupa matrik yang berisi user dan impressi pada masing-masing gambar sebanyak 239 matrik. Dari matrik tersebut kemudian dilakukan proses transpose metric. Selanjutnya dilakukan proses Automatic Clustering sehingga didapatkan impressi yang termasuk ke dalam outlier. Impressi yang terdeteksi outlier diberikan nilai nol. Kemudian matrik dilakukan proses transpose kembali untuk selanjutnya dilakukan proses perhitungan untuk mendapatkan impresi gambar.

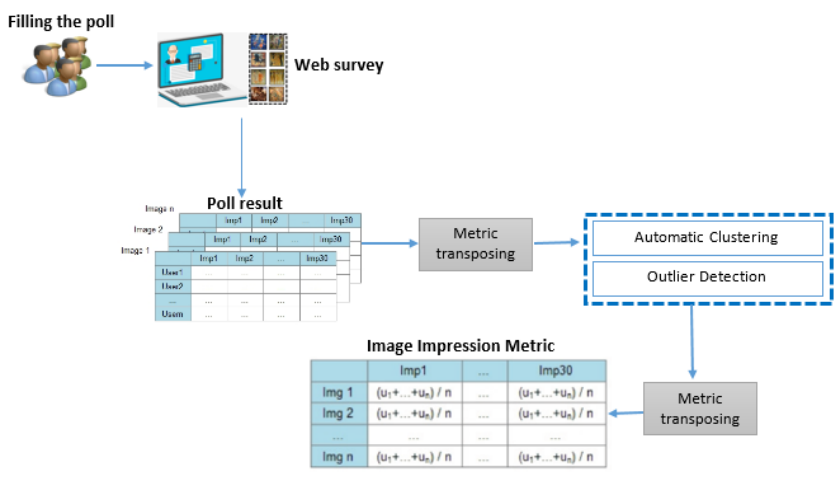

Gambar. 4.Proses Impresi Metrik gambar

Gambar 5 menjelaskan proses impression metric generation yang terdiri dari 3 matrik yaitu matrik warna impresi, impresi bentuk, dan impresi bentuk. Matrik ini diperoleh melalui proses men-transpose matrik tersebut. 
Hasil transpose kemudian dikalikan (inner product) dengan matrik fitur warna, matrik fitur bentuk, dan matrik fitur tekstur. Hasil perkalian menghasilkan matriks baru yang kemudian dilakukan proses deteksi outlier. Deteksi outlier menggunakan automatic clustering dengan range 1.5. Jarak rata-rata dari Centroid Cluster yang lebih besar dari $1.5 \mathrm{x}$ rata-rata maka akan terdeteksi outlier.
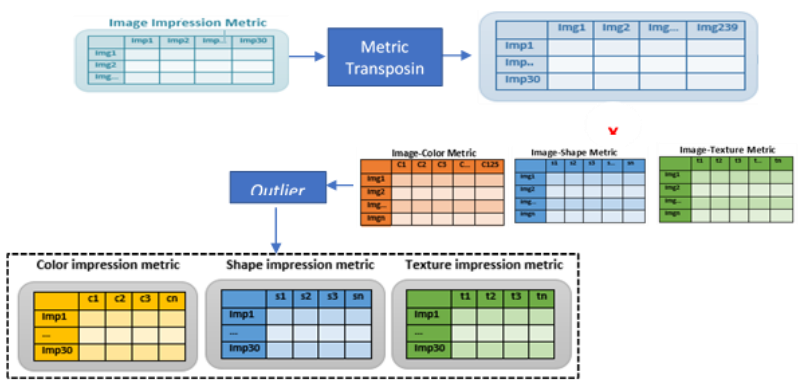

Gambar. 5.Proses Impression Metric Generation

F. Pendekatan Pengukuran

Dimodifikasi dari jarak manhattan yang menghubungkan perbedaan nilai atribut dengan nilai-nilai itu sendiri dikenal sebagai Canberra Distance [9].

$D_{(x, y)}=\sum_{i}^{N} \frac{\left|x_{i}-y_{i}\right|}{\left|x_{i}\right|+\left|y_{i}\right|}$

Dimana

$\mathrm{N}=$ jumlah atribut.

$x_{i}=$ metadata dari gambar query

$y_{i}=$ metadata dari gambar dataset

\section{HASIL PEMBAHASAN}

Hasil eksperimen terdiri dari 3 yaitu ekperimen similarity image, eksperimen aliran lukisan dan impressi lukisan.

a. Hasil Eksperimen Similarity Image

Pengujian Similarity Image peneliti menggunakan pendekatan error rasio dan scoring. Nilai error digunakan untuk mengetahui gambar query mana yang tidak sesuai. Nilai scoring digunakan untuk mengetahui nilai dari gambar yang sesuai atau tidak sesuai dengan image database.

Error $=\sum_{i=1}^{10} \operatorname{err}_{i}\left\{\begin{array}{c}\operatorname{err}_{i}=0 \leftarrow c r_{i}=c q \\ \operatorname{err}_{i}=1 \leftarrow \text { otherwise }\end{array}\right.$
Score $=\sum_{i=1}^{10} s c r_{i}\left\{\begin{array}{c}\operatorname{scr}_{i}=10-i+1 \leftarrow c r_{i}=c q \\ \operatorname{scr}_{i}=0 \leftarrow \text { otherwise }\end{array}\right.$

Dimana:

$C r_{i}=$ kategori dari gambar retrieval

$c q=$ kategori dari gambar query

\section{Warna}

Fitur warna pada penelitian ini menggunakan metode 3D-Color Quantization [10].

\begin{tabular}{|c|c|c|c|}
\hline Labels & $\begin{array}{c}\text { Average of } \\
\text { error }\end{array}$ & $\begin{array}{c}\text { Average of } \\
\text { accurasi }\end{array}$ & $\begin{array}{c}\text { Average of } \\
\text { scorring }\end{array}$ \\
\hline abstrak & 0.78 & 0.22 & 17.56 \\
\hline expressionisme & 0.59 & 0.41 & 27.73 \\
\hline naturalisme & 0.61 & 0.39 & 24.78 \\
\hline realisme & $\mathbf{0 . 2 4}$ & $\mathbf{0 . 7 6}$ & $\mathbf{4 3 . 1 1}$ \\
\hline romance & 0.77 & 0.24 & 17.05 \\
\hline Grand Total & $\mathbf{0 . 4 7}$ & $\mathbf{0 . 5 3}$ & $\mathbf{3 2 . 0 7}$ \\
\hline
\end{tabular}

Berdasarkan Tabel I. error terendah dan akurasi yang tertinggi yaitu pada aliran realisme. Hasil error rata-rata terendah adalah $24.13 \%$ dan akurasi rata-rata tertinggi adalah $75.87 \%$ (ditunjukkan dengan warna merah pada tabel). Sehingga nilai scorring tertinggi adalah aliran realisme. Hal itu menunjukkan bahwa performasi tertinggi terdapat pada label aliran realisme. Aliran realisme memiliki fitur warna yang dominan dibandingkan dengan aliran yang lain. Fitur warna yang dominan setelah aliran realisme adalah aliran ekspresionisme dengan nilai akurasi $41.43 \%$. Sedangkan untuk aliran yang lain memiliki akurasi yang lebih rendah yaitu aliran naturalisme memiliki akurasi $38.52 \%$, aliran romance $23.5 \%$, dan aliran abstrak $22.35 \%$.

\section{Bentuk}

Fitur bentuk pada penelitian ini menggunakan metode Connected Content Labelling. berdasarkan hasil perhitungan mean $(\mu)$, median, standard deviation $(\sigma)$ variance $\left(\sigma^{2}\right)$, dan skewness (s) dari implementasi kontur yang dihitung nilai area, equevalent diameter, extent, convex hull, solidity, eccentricity dan perimeter [11].

TABEL II. HASIL EKSPERIMEN EKSTRAKSI FITUR BENTUK

\begin{tabular}{|c|c|c|c|}
\hline Labels & $\begin{array}{c}\text { Average of } \\
\text { Error }\end{array}$ & $\begin{array}{c}\text { Average of } \\
\text { Accurasi }\end{array}$ & $\begin{array}{c}\text { Average of } \\
\text { Scorring }\end{array}$ \\
\hline Abstrak & 0.76 & 0.24 & 17.44 \\
\hline Expressionisme & 0.47 & 0.53 & 32.24 \\
\hline Naturalisme & 0.75 & 0.25 & 18.67 \\
\hline Realisme & $\mathbf{0 . 3 6}$ & $\mathbf{0 . 6 4}$ & $\mathbf{3 7 . 9 9}$ \\
\hline Romance & 0.76 & 0.25 & 17.90 \\
\hline Grand Total & $\mathbf{0 . 5 1}$ & $\mathbf{0 . 4 9}$ & $\mathbf{3 0 . 0 3}$ \\
\hline
\end{tabular}

Pada tabel di atas hasil esperimen menunjukkan performasi tertinggi terdapat pada label realisme. Error terendah adalah $35.87 \%$ dan akurasi tertinggi adalah $64.13 \%$ (ditunjukkan dengan tinta warna merah pada tabel). Scorring tertinggi adalah $37.99 \%$ pada label realisme. Hasil tersebut menunjukkan bahwa aliran bentuk memiliki fitur bentuk yang dominan. Secara visual lukisan dengan aliran realisme cenderung menunjukkan gambar objek secara jelas sehingga memudahkan sistem untuk deteksi bentuk

\section{Tekstur}

Fitur tekstur pada penelitian ini menggunakan metode Transformasi Gabor berdasarkan hasil perhitungan mean $(\mu)$, median, standard deviation $(\sigma)$, variance $\left(\sigma^{2}\right)$, dan skewness (s). Implementasi kernel Gabor penulis menggunakan 40 kernel. 


\begin{tabular}{|c|c|c|c|}
\hline Row Labels & $\begin{array}{c}\text { Average of } \\
\text { error }\end{array}$ & $\begin{array}{c}\text { Average of } \\
\text { accurasi }\end{array}$ & $\begin{array}{c}\text { Average of } \\
\text { scorring }\end{array}$ \\
\hline Abstrak & 0.74 & 0.26 & 18.76 \\
\hline Expressionisme & 0.42 & 0.58 & 35.08 \\
\hline Naturalisme & 0.66 & 0.34 & 23.00 \\
\hline Realisme & $\mathbf{0 . 3 7}$ & $\mathbf{0 . 6 3}$ & $\mathbf{3 7 . 6 0}$ \\
\hline Romance & 0.69 & 0.32 & 21.40 \\
\hline Grand Total & $\mathbf{0 . 4 9}$ & $\mathbf{0 . 5 1}$ & $\mathbf{3 1 . 4 0}$ \\
\hline
\end{tabular}

Berdasarkan hasil eksperimen menunjukkan bahwa label realisme lebih tinggi akurasinya di banding aliran yang lain. Error terendah adalah $37.16 \%$ dan akurasi tertinggi adalah $62.84 \%$ (ditunjukkan dengan tinta warna merah pada tabel). Scorring tertinggi adalah $37.60 \%$ pada label realisme. Hasil tersebut menunjukkan bahwa aliran realisme fitur teksturnya lebih dominan dibandingkan dengan aliran-aliran yang lain.

b. Hasil Eksperimen Deteksi Aliran

Hasil eksperimen untuk aliran menggunakan rasio error dan akurasi. Eksperimen deteksi aliran menggunakan metode K-Nearest Neighbor yaitu dengan mencari titik terdekat dari data baru (nearest neighbor). Teknik pencarian tetangga terdekat yang umum dilakukan dengan menggunakan formula euclidean distance kemudian ditentukan banyaknya $\mathrm{k}$ tetangga terdekat untuk melakukan klasifikasi data baru.

$$
d(x, y)=\sqrt{\sum_{i=0}^{n}\left(x_{i}-y_{i}\right)^{2}}
$$

Dimana:

$(\mathrm{x}, \mathrm{y})=$ jarak antara titik pada data gambar query $\mathrm{x}$ dan titik data gambar database y yang akan diklasifikasi

Berikut ini ditunjukkan hasil eksperimen untuk masingmasing nilai $\mathrm{k}$ mulai $\mathrm{k}=1, \mathrm{k}=2, \mathrm{k}=3$. Untuk eksperimen aliran ini terdapat hasil yang menggunakan proses normalisasi dan tanpa proses normalisasi. Proses normalisasi yang dipakai adalah softmax. Hasil akurasi bisa dilihat pada tabel berikut ini.

TABEL IV. HASIL EKSPERIMEN EKSTRAKSI FITUR TEKSTUR

\begin{tabular}{|c|c|c|c|c|}
\hline \multirow{2}{*}{} & \multicolumn{2}{|c|}{$\begin{array}{c}\text { Performance tanpa } \\
\text { normalisasi }\end{array}$} & \multicolumn{2}{c|}{$\begin{array}{c}\text { Performance setelah } \\
\text { normalisasi }\end{array}$} \\
\cline { 2 - 5 } & akurasi & eror & akurasi & eror \\
\hline K1 & $100 \%$ & $0 \%$ & $100 \%$ & $0 \%$ \\
\hline K3 & $64.02 \%$ & $35.98 \%$ & $67.78 \%$ & $32.22 \%$ \\
\hline K5 & $54.81 \%$ & $45.19 \%$ & $57.74 \%$ & $42.26 \%$ \\
\hline
\end{tabular}

\section{Eksperimen dengan Nilai $k=1$}

Pada eksperiment dengan nilai $\mathrm{k}=1$ hasil akurasi sebesar $100 \%$. Dan besar error rasio adalah $0 \%$.

\section{Eksperimen dengan Nilai $k=3$}

Eksperimen dengan nilai $\mathrm{k}=3$ menghasilkan akurasi sebesar 64.02. Dan besar eror rasio adalah $35.98 \%$. Setelah dinormalisasi dengan softmax hasil akurasi naik menjadi $67.78 \%$ dan eror rasionya yang besar yaitu $32.22 \%$.

\section{Eksperimen dengan Nilai $k=5$}

Eksperimen dengan nilai $\mathrm{k}=5$ menghasilkan akurasi sebesar $54.81 \%$. Dan besar eror rasio adalah $45.19 \%$. Setelah dinormalisasi dengan softmax hasil akurasi naik menjadi $57.74 \%$ dan eror rasionya yang besar yaitu $42.26 \%$. Dari hasil di atas dapat disimpulkan bahwa akurasi terbaik untuk mendapatkan aliran yaitu dengan data normalisasi menggunakan $\mathrm{KNN}$ dengan nilai $\mathrm{K}=3$.

c. Hasil Eksperimen Informasi Impressi Lukisan

Impresi yang ditampilkan dalam penelitian ini adalah impresi yang memiliki nilai paling mirip atau impresi yang dekat dengan image query. Dalam eksperimen informasi impressi lukisan ini menggunakan perhitungan presisi dan recall. Presisi adalah untuk menganalisis presisi antara image query dan impressi yang dihasilkan. Precision adalah tingkat ketepatan antara informasi yang diminta oleh user dengan jawaban yang dari sistem. Sedangkan recall adalah tingkat keberhasilan sistem dalam menemukan kembali sebuah informasi.

$$
\begin{aligned}
& P=\frac{T_{p}}{T_{p}+F_{p}} \\
& R=\frac{T_{p}}{T_{p}+F_{n}}
\end{aligned}
$$

Dimana:

$T_{p} \quad=$ Jumlah total impressi serupa diambil dengan impressi pada gambar query

$T_{p}+F_{p}=$ Total Jumlah impressi yang terkandung dalam gambar query

$T_{p}+F_{n}=$ Total impressi sebenarnya

TABEL V. HASIL EKSPERIMEN EKSTRAKSI FITUR TEKSTUR

\begin{tabular}{|c|c|c|c|}
\hline Image Query / Impresi & $\begin{array}{c}\text { Impressi di } \\
\text { dataset }\end{array}$ & $\begin{array}{c}\text { Hasil Pencarian } \\
\text { Sistem Berdasarkan } \\
\text { Fitur Warna }\end{array}$ & B/S \\
\hline & Aman & sepi,sunyi & 0 \\
& Bersemang & sedih,perih & 0 \\
& at & resah,risau & 0 \\
& Kejam,mar & bingung & 1 \\
& ah & damai,tenteram,tenang & 0 \\
& Kacau & menggoda & 0 \\
& Resah, & ragu & 0 \\
& risau & mengagumkan,mempe & 0 \\
& & sona & 0 \\
\hline & Presisi & menarik & $\mathbf{0 . 1}$ \\
\hline
\end{tabular}

Keterangan : B=Benar, S=Salah

Berdasarkan tabel $\mathrm{V}$, penentuan nilai benar atau salah didapatkan dari kesesuaian hasil pencarian system terhadap impresi yang ada di dataset. Sebagai contoh bernilai 1 jika benar data sesuai dengan impresi di dataset. Kemudian hasil benar salah akan didapatkan nilai presisi dan recall.

Menampilkan 10 impresi yang memiliki nilai tertinggi dari hasil pengukuran dengan menggunakan metode K-NN euclidean distance. 
TABEL VI. HASIL EKSPERIMEN EKSTRAKSI FITUR TEKSTUR

\begin{tabular}{|c|c|c|c|c|c|}
\hline image & presisi & recall & image & presisi & recall \\
\hline 220 & 0,2 & 0,67 & 230 & 0,1 & 0,33 \\
\hline 221 & 0,1 & 0,33 & 231 & 0 & 0 \\
\hline 222 & 0,2 & 0,67 & 232 & 0,1 & 0,33 \\
\hline 223 & 0,2 & 0,67 & 233 & 0 & 0 \\
\hline 224 & 0,2 & 0,67 & 234 & 0,3 & 1 \\
\hline 225 & 0,1 & 0,67 & 235 & 0,1 & 0,67 \\
\hline 226 & 0 & 0,33 & 236 & 0,3 & 1 \\
\hline 227 & 0,4 & 1 & 237 & 0,2 & 1 \\
\hline $\mathbf{2 2 8}$ & $\mathbf{0 , 5}$ & $\mathbf{1}$ & 238 & 0 & 0,33 \\
\hline 229 & 0,2 & 1 & 239 & 0,1 & 0,67 \\
\hline
\end{tabular}

Dari tabel VI nilai gambar dengan presisi tertinggi adalah gambar nomor 228 dengan besar presisi 0,5 . Tampilan gambar beserta impresi dapat dilihat dalam tabel berikut ini:

TABEL VII. TAMPILAN GAMBAR BESERTA IMPRESI NILAI PRESISI TERTINGGI LUKISAN ALIRAN ROMANTISME

\begin{tabular}{|c|c|c|}
\hline $\begin{array}{c}\text { Identitas } \\
\text { Gambar }\end{array}$ & Gambar Lukisan & Impresi \\
\hline 228 & & $\begin{array}{c}\text { Sombong, angkuh, } \\
\text { kejam,marah,khilaf }\end{array}$ \\
& & \\
& & \\
& &
\end{tabular}

Impressi yang disediakan mengacu pada penelitian sebelumnya [3] yaitu sebanyak 30 impressi diantaranya aman, suci, mulia, khawatir, sabar, damai, tenteram, tenang, bersemangat, dengki, cemburu, cinta, menggoda, putus asa, bingung, sedih, perih, sombong, angkuh, letih, kacau, khilaf, ikhlas, cantik, indah, ragu, mengagumkan, mempesona, malu, segan, curiga, romantic, sepi, sunyi , resah, risau, kejam, marah, sopan, nekat, menarik gembira, senang.

Analisa dilakukan dengan melakukan ekstraksi fitur warna dari data berdasarkan 30 impressi. Kemudian dilakukan pencocokan dengan impresi yang dihasilkan oleh ekstraksi color data. Impresi data diambil 10 nilai tertinggi dari setiap fitur impresi. Nilai tertinggi presisi adalah 0,6.

Penelitian ini akan menghasilkan 3 luaran yaitu sebuah informasi berupa impressi dari lukisan budaya Indonesia, pengelompokan aliran dari sebuah lukisan, dan pendekatan gambar lukisan yang serupa. Dengan tingkat akurasi pendekatan fitur warna yaitu $75.87 \%$ dimana lebih tinggi dibandingkan dengan penelitan [3] yaitu kurang lebih $60 \%$.

\section{KESIMPULAN}

Berdasarkan percobaan yang telah dilakukan maka dapat diambil beberapa kesimpulan sebagai berikut. Pendekatan gambar lukisan budaya fitur warna memiliki akurasi tertinggi dibandingkan dengan fitur bentuk dan tekstur yaitu sebesar $75.87 \%$. Sedangkan fitur bentuk sebesar $64.13 \%$ dan fitur tekstur sebesar $62.84 \%$. Akurasi tertinggi ketiga fitur pada pendekatan gambar lukisan budaya terletak pada lukisan dengan aliran realisme. Secara visual lukisan dengan aliran realisme cenderung menunjukkan gambar objek secara jelas sehingga memudahkan sistem untuk deteksi bentuk, warna, dan tekstur. Eksperimen dengan nilai $\mathrm{k}=3$ sebelum data dinormalisi menghasilkan akurasi sebesar $64.02 \%$. Setelah dinormalisasi dengan softmax hasil akurasi naik menjadi 67.78\%. 4. Nilai Presisi dari deteksi impresi lukisan yang paling tinggi sebesar 0,6 pada lukisan nomor 116 yang beraliran realism, lukisan nomor 156 yang beraliran ekspresionisme, dan lukisan nomor 213 yang beraliran romantisme.

Dengan penelitian ini dapat memberikan manfaat berupa kemudahan dalam memperoleh impressi dari lukisan budaya, menampilkan pendekatan dari gambar query, serta pendeteksian aliran dari lukisan budaya Indonesia. Pada penelitian selanjutkan diharapkan peneliti dapat mengoptimalkan masing-masing teknik ekstraksi fitur terutama fitur bentuk dan tekstur karena peneliti masih mendapatkan akurasi rendah pada fitur bentuk sebesar 64.13 $\%$ dan fitur tekstur sebesar $62.84 \%$. Serta mengoptimasi teknik saat implementasi tiap tahapan metode agar tidak membutuhkan waktu yang lama untuk mendapatkan hasil saat menggunakan aplikasi mobile.

\section{REFERENSI}

K. Umam, A. R. Barakbah, and A. Basuki, "Semantic image search system of madurese cultural batik with impression, color and shape features," 2016 Int. Conf. Knowl. Creat. Intell. Comput. KCIC 2016, pp. 28-34, 2017, doi: 10.1109/KCIC.2016.7883621.

[2] D. Amirullah, A. R. Barakbah, and A. Basuki, "Semantic Songket Image Search with Cultural Computing of Symbolic Meaning Extraction and Analytical Aggregation of Color and Shape Features," vol. 5, no. 1, pp. 1-18, 2017.

D.N.Kuswara, A.R.Barakah, N.R.Mubtadai,and Y.Setiowati, "Impression Generation of Indonesian Cultural Paintings for Mobile Application with Culture Dependent Color-Impression Metric Creation Contents", vol.1, no 2,pp.75-90,2014.

[4] A. R. Barakbah, I.Y.Suryani,E.M.Kusumaningtyas," A CultureOriented Image Search System for Indonesian Cultural Paintings with Semantic Multi-Query Analytical Function", The Second Indonesian-Japanese Conference on Knowledge Creation and Intelligent Computing (KCIC) 2013, 20-21 March 2013, Bali, Indonesia.

[5] Z.Zulmartin,"Peningkatan Prestasi Belajar Dan Nilai Afektif Siswa Melalui Model Pembelajaran Kooperatif Tipe Jigsaw Pada Materi Pelajaran Apresiasi Seni Lukis Kelas X Mia 4, Sma 32 Jakarta Semester 2 Tahun 2014/2015",vol.03,no 2,pp.143154,2016 .

[6] A. R. Barakbah and Y. Kiyoki, "IMAGE RETRIEVAL SYSTEMS WITH 3D-COLOR VECTOR QUANTIZATION AND CLUSTER BASED SHAPE AND STRUCTURE FEATURE EXTRACTION System Design Color Feature Extraction Shape \& Structure Feature Extraction,” p. 1000.

[7] A. A. Kurniasari, A. R. Barakbah, and A. Basuki, "ContentDependent Image Search System for Aggregation of Color, Shape and Texture Features," Emit. Int. J. Eng. Technol., vol. 7, no. 1, pp. 223-242, 2019, doi: 10.24003/emitter.v7i1.361. 
[8] A. Nurhadiyatna, A. L. Latifah, and D. Fryantoni, "Gabor filtering for feature extraction in real time vehicle classification system," 9th Int. Symp. Image Signal Process. Anal. ISPA 2015, no. Ispa, pp. 19-24, 2015, doi: 10.1109/ISPA.2015.7306026.

[9] A.F.Pulungan,M.Zarlis, and S.Suwilo. "Analysis of Braycurtis, Canberra and Euclidean Distance in KNN Algorithm". Vol.4, no.1, pp 74-77. Journal Publications \& Informatics Engineering Research.2019. Sinkron.Politeknik Ganesha Medan. DOI : https://doi.org/10.33395/sinkron.v4i1.10207.

[10] G.Ramella and G.S.D.Baja, "A new method for color quantization",12th International Conference on Signal-Image Technology \& Internet-Based Systems.2016. of Connected Component Labelling for Calculation Amount of Eggs on the Laying Pullet Cage", The 3rd EPI International Conference on Science and Engineering 2019 (EICSE2019). IOP Conf. Series: Materials Science and Engineering 875 (2020) 012090 IOP Publishing doi:10.1088/1757899X/875/1/012090.2020. 